\title{
Health professionals' acceptance and willingness to pay for hepatitis B virus vaccination in Gondar City Administration governmental health institutions, Northwest Ethiopia
}

\author{
Siwule Abiye ${ }^{1}$, Mezgebu Yitayal ${ }^{2^{*}}$ (D) Giziew Abere $^{3}$ and Asefa Adimasu ${ }^{4}$
}

\begin{abstract}
Background: Hepatitis B virus (HBV) infection is a global public health problem. The burden of the disease is high in low and middle income countries like Ethiopia. However, for highly vulnerable groups such as health professionals, vaccination coverage is a major issue in the developing countries where health professionals are expected to pay for vaccination. Therefore, the objective of this study was to assess health professionals' acceptance and willingness to pay (WTP) and associated factors for vaccination against HBV.
\end{abstract}

Methods: Cross-sectional study was conducted from March to April, 2017 in Gondar city administration governmental health institutions among 423 health professionals. Simple random sampling method was employed to select the study participants. Data were collected using self- administered questionnaire. Tobit model was used to analyze the determinants of WTP and the maximum amount of money the individuals might pay for HBV vaccination. P-value < 0.05 was considered statistically significant.

Result: A total of 423 health professionals (physicians, nurses, midwives, laboratory technicians/technologists, and others) participated in the study with a response rate of 100 , and $62.4 \%$ of them were willing to pay for HBV vaccination. The mean amount of money the participants might pay for HBV vaccination was $325.83 \pm$ 283.46 ETB (US\$ $14.39 \pm 12.52$ ). The study indicated that the WTP for HBV vaccination of health professionals from health centers was 179.41 ETB less compared to health professionals from hospital. The WTP for HBV vaccination of the participants who had no experience of seeing previous patients with HBV was 157.87 ETB less compared to participants who had experience of seeing previous patients with HBV. As monthly income of the study participants increased by one ETB, the WTP was increased by 0.027 ETB.

Conclusion: The study revealed that the mean amount of money the participants might pay for HBV vaccination was much less than the market price for HBV vaccination. Type of workplace and experience of seeing/observing patients with HBV, and income were the predictors of WTP for HBV vaccination. Availing the vaccine with affordable cost in governmental health institutions may increase WTP of health professionals for HBV vaccination.

Keywords: Health professionals, Willingness to pay, Hepatitis B virus, Vaccination, Gondar city administration, Ethiopia

\footnotetext{
* Correspondence: mezgebuy@gmail.com

${ }^{2}$ Department of Health Systems and Policy, Institute of Public Health, College

of Medicine and Health Sciences, University of Gondar, P. O. Box 196,

Gondar, Ethiopia

Full list of author information is available at the end of the article
}

(c) The Author(s). 2019 Open Access This article is distributed under the terms of the Creative Commons Attribution 4.0 International License (http://creativecommons.org/licenses/by/4.0/), which permits unrestricted use, distribution, and reproduction in any medium, provided you give appropriate credit to the original author(s) and the source, provide a link to the Creative Commons license, and indicate if changes were made. The Creative Commons Public Domain Dedication waiver (http://creativecommons.org/publicdomain/zero/1.0/) applies to the data made available in this article, unless otherwise stated. 


\section{Background}

Hepatitis B infection is highly infectious disease caused by Hepatitis B virus (HBV) that can be acute or chronic with illness severity from asymptomatic to symptomatic degenerative disease. It is a major public health challenge in the world infecting more than 66,000 health professionals each year $[1,2]$. Vaccination against Hepatitis B saves the lives of these health professionals [3]. Around $45 \%$ of the global population live in high HBV infection prevalence $(>8 \%)$ areas $[1,4]$. Acute HBV has a case fatality rate of $0.5-1 \%[3,5]$. Worldwide, 2 billion people have evidence of past or present infection with HBV [6], and 360 million are chronic carriers of HBV surface antigen [2,7], and more than 686,000 people die each year from its complications [8]. Overall, HBV infection reported more in lower and middle income countries [1, 2, 9] causing a significant economic burden in terms of years of life lost [2].

Health care workers (HCWs) exposed to HBV infection were reported to be about $5.9 \%$ and the risk of contracting HBV by HCWs is fourfold higher as compared to general adult population [10,11]. A study conducted in Ras Desta and Tikur Anbessa Hospitals in Addis Ababa, Ethiopia revealed that hepatitis surface antigen was detected in $9.7 \%$ of the HCWs [12]. Studies revealed that only $20(5.4 \%)$ respondents in a study conducted among 370 respondents in Bahir Dar city administration, North West Ethiopia [13], and 53 (12.9\%) in a study conducted among $423 \mathrm{HCWs}$ in Shashemene town, Ethiopia [14] took three or more doses of hepatitis B vaccine. Another study conducted on Ethiopian surgeons' vaccination status showed that only $18.36 \%$ received the three doses of the vaccination [15].

The most effective and feasible means of prevention for HBV is vaccination and avoidance of blood and other potentially infectious fluids [1]. World Health Organization (WHO) recommends all $\mathrm{HCW}$ s should be vaccinated against HBV in high epidemic areas of HBV [16]. Evidences show that $\mathrm{HBV}$ vaccine coverage of health care workers is low $[3,5,15,17]$; and the reasons for not being vaccinated are lack of money, lack of awareness about the availability of the vaccine, time, perception that vaccine is not important and not at risk, negligence; work load, negligence, and peer pressure $[3,10,11,17,18]$. Though the Ethiopian Ministry of Health and other global agencies recommend that all health professionals should be vaccinated against $\mathrm{HBV}$ vaccine before starting the clinical attachments during their stay in the medical school [19], a study conducted in Amhara Regional State hospitals showed that only $4 \%$ vaccine coverage and unaffordable vaccine cost was the major reason for not being vaccinated [20].

Though limited evidences are available on health professionals' WTP for HBV vaccination, evidences are available on WTP for vaccinations against other viruses such as Dengue virus, Tick-borne Encephalitis virus, Influenza virus, and Zika virus. These evidences show that sex, age, marital status, educational status, occupation, monthly income, residence, knowledge and attitude towards the vaccine, time consumed, perceived risk, disease related knowledge, severity of the disease, peer pressure, and medical advice are factors associated with willing to pay for vaccination [21-26].

However, health workers' acceptance and WTP for HBV vaccination and their determinants have not yet been studied. Therefore, this study aimed to assess the health workers' acceptance and WTP for vaccination of HBV and its determinant factors.

\section{Methods}

\section{Study design and setting}

Institution based cross sectional study was conducted to assess the health professionals' WTP and associated factors for vaccination against HBV. The study was conducted from April to May, 2017 in Gondar city Administration Governmental health institutions, North Gondar zone, Amhara Regional State, Ethiopia. Gondar city administration has 12 sub-city administrations with population of 300,000 and has 8 health centers (health facilities which are staffed by around 20 professionals and provide preventive, curative, inpatient and ambulatory services, treatment of common psychiatric disorders, and dental services for 15,000-25,000 people in rural areas, and around 40,000 people in urban areas) [27], and one referral hospital. There were about 1529 health professionals (medical doctors, nurses, midwives, laboratory technologists, and others) working in these health institutions.

\section{Study population and sampling procedures}

The study population was all health professionals who were working in the hospital and health centers. All health professionals working in the hospital and health centers during the study period were included in the study whereas health professionals who were fully vaccinated for HBV, who were HBV positive, and who were critically ill were excluded from the study.

The sample size was determined using single population proportion formula by taking 50\% proportion, $95 \%$ CI, $5 \%$ margin of error, and $10 \%$ non-response rate.

$$
\begin{aligned}
\mathrm{N} & =(\mathrm{Z} \alpha / 2)^{2} * \mathrm{P} *(1-\mathrm{p}) / \mathrm{w} 2 \\
& =(1.96) 2 * 0.5 *(1-0.5) / 0.025=384.16
\end{aligned}
$$

The final sample size was $384.16+38.414$ (response rate) $=422.576 \approx 423$.

The sample was allocated proportionally to the 9 health institutions. In order to select the study 
participants, all the 9 health facilities available in the study area were considered, the sample was allocated to each health facility proportional to the number of health professionals in each health facility, and simple random sampling technique by using lottery method was used to select the study participants from each health facility.

\section{Study variables}

\section{Response variable}

The response variables in this study were acceptance and WTP for HBV vaccination. Acceptance for HBV vaccination was measured by asking the respondents: "Are you willing to pay for HBV vaccination?" The alternative options were: "Yes" or "No". WTP was defined as the maximum amount of money that individuals were willing to pay for HBV vaccination and it was measured by the bid contingent value method. The respondents were first asked whether they would be willing to pay a specific amount (192 ETB $=7.11$ USD) and then the question was repeated using a higher or lower bid value depending on the response to the first question until the response of maximum/minimum amount the health professionals willing to pay was reached.

\section{Explanatory variables}

The socio-demographic and economic characteristics of the study participants such as age, sex, religion, ethnicity, marital status, educational status, occupation, work place, years of experience, and monthly income were collected. The age was recorded based on the response of the respondents. The educational status was defined as the highest level of formal education completed. The occupation of study participants was classified based on the main job of the participants: medical doctor, health officer, nursing, midwifery, laboratory technology, pharmacy, anesthesia, optometry, and other (specify). The work place was categorized as hospital and health center. Monthly income of the study participants was defined as the average amount of money earned by participants each month. Other explanatory variables such as special training about HBV, medical advice about HBV, and having experience of seeing patients who have HBV were assessed using "Yes" or "No" questions. Medical advice is the provision of a formal professional opinion or guidance or recommendations from a doctor, nurse, or other healthcare professional regarding what a specific individual should or should not do to restore or preserve health.

\section{Data collection procedures}

A pretested and standardized questionnaire was used. The tool was prepared by reviewing factors on WTP for HBV vaccination and associated factors (Additional File 1). The socio-demographic, economic, and service and knowledge related factors were addressed. The WTP tool was prepared by using the contingent valuation method (CVM). For data collection, five nurses supervised by two supervisors were assigned with the principal investigator critical follow up. The data collectors and supervisors were approached by the principal investigator and took the data collection training if they agreed to participate in the data collection process. The data collectors and supervisors were trained for 2 days on data collection procedures.

Pre-test was conducted on 42 (10\% of the sample) health professionals who were advance extension students in University of Gondar who came from Gondar Zuria health centers; and necessary modification was done after pre-test. Then, in the final data collection, the study participants assisted by the data collectors filled in the questionnaire. The collected data were checked by the data collectors' supervisors as well as the principal investigator.

\section{Data processing and analysis}

The data were entered into Epi Info version 7 software and exported to STATA version 14 for analysis. The data was described using frequencies and means to show distribution of the WTP and associated factors. Tobit model was used to analyze the determinants of WTP and the maximum amount of money that individuals might pay for HBV vaccination. The maximum amount of money the respondents might pay is given by:

$$
\begin{aligned}
\mathrm{Y} & =1 \text { if } \mathrm{MWTP}=\beta_{0}+\beta_{\mathrm{i}} \mathrm{X}_{\mathrm{i}}+\varepsilon>0 \text {, and } \mathrm{Y} \\
& =0 \text { if } \mathrm{MWTP} \leq 0
\end{aligned}
$$

Where $\mathrm{Y}=\mathrm{WTP}$ for $\mathrm{HBV}$ vaccination; MWTP $=$ Maximum WTP; $X_{i}=$ Explanatory variables; $\beta_{0}=$ Slope; $\beta_{i}=$ Coefficient; $\varepsilon=$ error term; $1=$ Success $/$ Yes; $0=$ Failure $/$ No.

The model estimates marginal effect of an explanatory variable on the expected value of the WTP for HBV vaccination. A $p$-value $=0.05$ was used to determine statistical significance.

\section{Results}

\section{Socio-demographic characteristics of study participants}

A total of 423 respondents participated in this study with a response rate of $100 \%$ as the study participants involved in the study were health professionals who were aware of the public health importance of HBV vaccination and supported the purpose of this study. Among the respondents, $52.2 \%$ were males, $83.9 \%$ were Orthodox Christians, and $46.8 \%$ were nurses. The mean age and monthly income of the respondents was $29.24 \pm$ 6.09 years, and $6180.23 \pm 2247.81$ ETB (US\$ $272.97 \pm$ 99.28), respectively (Table 1). 
Table 1 Socio-demographics characteristics of study participants, Gondar City Administration Governmental Health Institutions, Northwest Ethiopia, $2017(N=423)$

\begin{tabular}{|c|c|c|}
\hline Variable & Frequency (n) & Percentage (\%) \\
\hline \multicolumn{3}{|l|}{ Sex } \\
\hline Male & 221 & 52.2 \\
\hline Female & 202 & 47.8 \\
\hline \multicolumn{3}{|l|}{ Age (year) } \\
\hline $21-30$ & 329 & 77.8 \\
\hline $30-40$ & 69 & 16.3 \\
\hline$>40$ & 25 & 5.9 \\
\hline \multicolumn{3}{|l|}{ Religion } \\
\hline Orthodox & 355 & 83.9 \\
\hline Muslim & 52 & 12.3 \\
\hline Others & 16 & 3.8 \\
\hline \multicolumn{3}{|l|}{ Work place } \\
\hline Hospital & 377 & 89.1 \\
\hline Health center & 46 & 10.9 \\
\hline \multicolumn{3}{|l|}{ Marital status } \\
\hline Single & 227 & 53.7 \\
\hline Married & 186 & 44.0 \\
\hline Others & 10 & 2.3 \\
\hline \multicolumn{3}{|l|}{ Occupation } \\
\hline Physician & 91 & 21.5 \\
\hline Nurse & 198 & 46.8 \\
\hline Midwife & 66 & 15.6 \\
\hline Laboratory & 21 & 5 \\
\hline Others & 47 & 11.1 \\
\hline \multicolumn{3}{|l|}{ Educational level } \\
\hline Diploma & 29 & 6.9 \\
\hline First degree & 327 & 77.3 \\
\hline Second degree & 61 & 14.4 \\
\hline PhD and above & 6 & 1.4 \\
\hline \multicolumn{3}{|l|}{ Years of Experience } \\
\hline$<5$ Years & 257 & 60.8 \\
\hline 5-10 Years & 126 & 29.8 \\
\hline$>10$ Years & 40 & 9.4 \\
\hline \multicolumn{3}{|c|}{ Monthly income (ETB) } \\
\hline$<5000.00$ & 132 & 31.2 \\
\hline 5000-10,000.00 & 266 & 62.9 \\
\hline$>10,000.00$ & 25 & 5.9 \\
\hline
\end{tabular}

\section{Health professionals' acceptance and WTP for HBV} vaccination

There were $62.4 \%$ study participants who were willing to pay for HBV vaccination. The mean amount of money the participants might pay for HBV vaccination was $325.83 \pm 283.46$ ETB (US\$ $14.39 \pm 12.52$ ). Among 264 participants who were willing to pay for $\mathrm{HBV}$ vaccination, 71 (26.9\%) were physicians, 122 (46.2\%) nurses, 31 (11.7\%) midwives, 10 (3.8\%) laboratory technicians/technologists and $30(11.4 \%)$ other health professionals. The majority (97.6\%) of study participants did not take special training about HBV.

The reasons for not being willing to pay for HBV vaccination among health professionals were the perception that the HBV vaccine may not be available in the health institutions (47.8\%), considering not being at risk of HBV infection (10.1\%), lack of awareness about the availability of $\mathrm{HBV}$ vaccine $(16.4 \%)$, peer pressure $(8.8 \%)$, lack of time $(3.8 \%)$, and the vaccination process is time consuming (9.4\%) (Table 2).

\section{Factors associated with WTP for HBV vaccination}

The study revealed that workplace and experience of seeing/observing previous patients with $\mathrm{HBV}$ and income were factors associated with WTP for HBV vaccination. The study indicated that the WTP for HBV vaccination of health professionals from health centers was 179.41 ETB less compared to health professionals from hospital. The WTP for HBV vaccination of the participants who were from health centers was $19.39 \%$ less than those respondents who were from the hospital $(P<$ 0.05 , average marginal effect $=-.1939135)$. The WTP for HBV vaccination of the participants who had no experience of seeing previous patients with HBV was 157.87 ETB less compared to participants who had experience of seeing previous patients with HBV. The WTP for HBV vaccination of participants who had no experience of seeing previous patients with $\mathrm{HBV}$ was $17.13 \%$ less compared to participants who had experience of seeing previous patients with $\mathrm{HBV}(P<0.01$, average marginal effect $=-.1713363)$. As the monthly salary of the study participants increased by one ETB, the WTP was increased by 0.027 ETB. As monthly salary of the participants increased by $1000.00 \mathrm{ETB}$, the WTP for HBV vaccination increased by $3.70 \%(P<0.000$, average marginal effect $=0.000037)($ Table 3$)$.

\section{Discussion}

This study revealed that $62.4 \%$ of health professionals were willing to pay for self-paid HBV vaccination. The mean amount of money the participants were willing to pay for HBV vaccination was $325.83 \pm 283.46$ ETB (US\$ $14.39 \pm 12.52)$. This is much less than the market price for HBV vaccination which is around 900 ETB (US\$ 33.33). Among those who were willing to pay for $\mathrm{HBV}$ vaccination, $8.7 \%$ participants agreed to pay below the average vaccine price which may due to unaffordable vaccine price. This could be due to the fact that health professionals are underpaid in Sub-Saharan Africa [20]. Moreover, high cost is the main obstacle for not being- 
Table 2 Acceptance and reasons for not being willing to pay for HBV vaccination, Gondar City Administration Governmental Health Institutions, Northwest Ethiopia, 2017 ( $N=423)$

\begin{tabular}{|c|c|c|}
\hline Variable & $\begin{array}{l}\text { Frequency } \\
\text { (n) }\end{array}$ & $\begin{array}{l}\text { Percentage } \\
(\%)\end{array}$ \\
\hline \multicolumn{3}{|l|}{ Do you want to pay for HBV vaccination? } \\
\hline Yes & 264 & 62.4 \\
\hline No & 159 & 37.6 \\
\hline \multicolumn{3}{|c|}{ Why do not you want to pay for HBV vaccination? } \\
\hline The vaccine is not available & 76 & 47.8 \\
\hline Not at risk of acquiring the virus & 16 & 10.1 \\
\hline $\begin{array}{l}\text { Not aware about the availability of the } \\
\text { vaccine }\end{array}$ & 26 & 16.4 \\
\hline Peer pressure & 14 & 8.8 \\
\hline Lack of time & 6 & 3.8 \\
\hline Vaccination process is time consuming & 15 & 9.4 \\
\hline Others & 6 & 3.8 \\
\hline
\end{tabular}

vaccinated especially in low- income countries like Ethiopia where the prevalence of hepatitis B virus is high particularly among vulnerable groups (health professionals) [28]. Health institutions should avail the vaccine with affordable cost for health professionals [29].

On the other hand, in the current study, $37.6 \%$ of participants were not willing to pay for self-paid HBV vaccination. The main reasons for not willing to pay for HBV vaccination were unavailability of $\mathrm{HBV}$ vaccine (47.8\%) from health institutions, considering not being at risk of HBV infection, lack of awareness about the availability of $\mathrm{HBV}$ vaccine, peer pressure, lack of time, and the vaccination process is time consuming. In this study, unavailability of the vaccine hampered acceptance for HBV vaccination in $47.8 \%$ of participants. This finding is in accordance with a study conducted in Amhara National Regional Sate hospitals where lack of access to the vaccine was the main reason for a high nonvaccination rate among health professionals [20].

The study revealed that factors such as workplace and experience of seeing/observing patients with HBV, and income were significantly associated with WTP for HBV vaccination. Health professionals who were working in the health centers had less WTP for HBV vaccination compared with those who were working in the hospital. An increased WTP for HBV vaccination was seen among who were working in the hospital could be due to an increased awareness about the risk of HBV infection, prevention methods and advantage of being vaccinated. It is very vital raising the awareness of health care workers about the importance of being vaccinated against $\mathrm{HBV}$ and providing adequate information about $\mathrm{HBV}$ vaccine is important for risky group of population $[3,30]$.

Similarly, a decrease in WTP for HBV vaccination was seen among study participants who had no experience of seeing/ observing patients with HBV compared with study participants who had experience of seeing/observing patients with HBV. This could be related to the perceived seriousness or severity of the disease as reported in other study on WTP for cervical cancer screening [31].

Table 3 Factors associated with WTP for HBV vaccination, Gondar City Administration Governmental Health Institutions, Northwest Ethiopia, 2017 ( $\mathrm{N}=423)$

\begin{tabular}{|c|c|c|c|c|c|c|}
\hline$\overline{\text { WTP }}$ & Coef. & Std. Err. & $t$ & $P>|t|$ & 95\% Conf. Interval & Marginal Error $=P(d y / d x)$ \\
\hline Age & -5.02 & 5.48 & -0.92 & 0.360 & $-15.79,5.75$ & \\
\hline \multicolumn{7}{|l|}{ Work Place } \\
\hline Health Center & -179.41 & 72.14 & -2.49 & 0.013 & $-321.21,-37.61$ & -.1939135 \\
\hline \multicolumn{7}{|l|}{ Occupation } \\
\hline Nurse & -43.69 & 65.15 & -0.67 & 0.503 & $-171.76,84.38$ & \\
\hline Midwife & -120.20 & 78.55 & -1.53 & 0.127 & $-274.60,34.21$ & \\
\hline Lab. Technicians & -35.98 & 106.27 & -0.34 & 0.735 & $-244.87,172.92$ & \\
\hline Others & 42.34 & 78.36 & 0.54 & 0.589 & $-111.70,196.37$ & \\
\hline Experience & -3.17 & 5.43 & -0.58 & 0.560 & $-13.85,7.51$ & \\
\hline Income & .027 & .011 & 2.36 & 0.018 & $.005, .049$ & .000037 \\
\hline \multicolumn{7}{|l|}{ Medical Advice } \\
\hline No & -43.50 & 41.79 & -1.04 & 0.298 & $-125.65,38.64$ & \\
\hline \multicolumn{7}{|l|}{ Previous IIIness } \\
\hline No & -157.87 & 50.59 & -3.12 & 0.002 & $-257.30,-58.43$ & -.1713363 \\
\hline _Constant & 207.82 & 150.64 & 1.38 & 0.168 & $-88.29,503.93$ & \\
\hline /sigma & 367.73 & 17.29 & & & $333.74,401.71$ & \\
\hline
\end{tabular}


Finally, as the income of the study participants increases, the WTP for HBV vaccination also increases. This might be related to the fact that those having more income may have additional money to allocate for promotion of their health in addition to meeting their basic needs. This is in line with a study done in Pakistan on WTP for vaccination against HBV and its determinants [32] and studies conducted on WTP for different health care services in Addis Ababa [33], Malaysia [34], and Iran [35].

\section{Limitation of the study}

The method used in this study is partial economic evaluation approach which does not show net benefit of the HBV vaccination since the study did not account for other costs and benefits of HBV vaccination. There might also be response bias in which respondents intentionally prefer lower costs of $\mathrm{HBV}$ vaccination to ensure that the set price is low when currently free services end. Finally, due to lack of published evidences on WTP for self-paid HBV vaccination, particularly among health professionals, comparison with previous research findings was limited. The other limitation of the study was that we could not measure the actual monthly income of the study participants which might overestimate or underestimate the WTP for HBV vaccination.

\section{Conclusion}

The study revealed that the mean amount of money the participants were willing to pay for HBV vaccination was much less than the market price for HBV vaccination. Place of work and experience of seeing/observing patients with HBV and income were the predictors of WTP for HBV vaccination. Availing the vaccine with affordable cost in governmental health institutions such as hospitals and health centers may increase WTP of health professionals for HBV vaccination.

\section{Supplementary information}

Supplementary information accompanies this paper at https://doi.org/10. 1186/s12913-019-4671-3.

Additional file 1. Information Sheet and Consent Form, and Questionnaire on Health professionals' willingness to pay for Hepatitis B virus vaccination in Gondar City Administration Governmental Health Institutions, Northwest Ethiopia.

\section{Abbreviations}

AOR: Adjusted Odds Ration; CVM: Contingent Valuation Method; HBV: Hepatitis B Virus; HCWs: Health Care Workers; HIV: Human Immunodeficiency Virus (HIV); WHO: World Health Organization; WTP: Willingness to Pay

\section{Acknowledgements}

We are very thankful to the University of Gondar for the approval of the ethical issue and its technical and financial support. We would like to thank the study participants, data collectors and supervisors for their participation in the study.

\section{Authors' contributions}

SA designed the study, developed data collection tools, performed the analysis and interpretation of data and drafted the paper. MY, GA and AA participated in the development of the study proposal, analysis and interpretation, revised drafts of the paper, revised the manuscript. All authors read and approved the final manuscript.

\section{Funding}

This is part of a master thesis funded by University of Gondar. The preliminary findings of this study were presented at Institute of Public Health, University of Gondar. After incorporating the comments, the authors have prepared this manuscript for publication at BMC Health Service Research. The funders had no role in the study design, data collection and analysis, decision to publish, or preparation of the manuscript.

\section{Availability of data and materials}

The datasets supporting the conclusions of this article are available upon request to the corresponding author. Due to data protection restrictions and participant confidentiality, we do not make participants data publicly available.

\section{Ethics approval and consent to participate}

Study was conducted after ethical approval was obtained from the Ethical Review Board of the Institute of Public Health, College of Medicine and Health Science, University of Gondar. Official letters of permission were also obtained from the University of Gondar hospital and from Gondar City Administration Health Office. All the study participants were oriented on the objectives and purpose of the study prior to study participation. The study participants were requested for verbal consent only as the study had minimal risk to the study participants. In order to get their verbal consent, we read off the information sheet and consent form for each participant. The protocol of the study including the verbal consent was approved by the Institute of Public Health Ethical Review Board, University of Gondar. Confidentiality and anonymity were ensured. Study participants were informed that participation had no impact on the provision of their health care. Study team members safe guarded the confidentiality and anonymity of study participants throughout the entire study. All forms and data related to the study were stored in a locked room in a secured area, with controlled access available only to the investigators. Participation in the study was voluntary and individuals were free to withdraw or stop the interview at any time.

\section{Consent for publication \\ Not applicable.}

\section{Competing interests}

The authors declare that they have no competing interests.

\section{Author details}

'University of Gondar Referral Hospital, College of Medicine and Health Sciences, University of Gondar, Gondar, Ethiopia. ²Department of Health Systems and Policy, Institute of Public Health, College of Medicine and Health Sciences, University of Gondar, P. O. Box 196, Gondar, Ethiopia. ${ }^{3}$ Department of Environmental and Occupational Health and Safety, Institute of Public Health, College of Medicine and Health Sciences, University of Gondar, Gondar, Ethiopia. ${ }^{4}$ Department of Epidemiology and Biostatistics, Institute of Public Health, College of Medicine and Health Sciences, University of Gondar, Gondar, Ethiopia.

Received: 20 March 2019 Accepted: 23 October 2019

Published online: 05 November 2019

\section{References}

1. Afework G. Knowledge, Attitude and Practice of Hepatitis B Virus and Its Vaccination Among Health Care Professionals in Selected Public Hospitals of Addis Ababa, Ethiopia. 2015. https://pdfs.semanticscholar.org/0546/5382 0345636a48eb959b722c49f59a350c0c.pdf

2. WHO Guidelines Approved by the Guidelines Review Committee. Guidelines for the Prevention, Care and Treatment of Persons with Chronic Hepatitis B Infection. Geneva: World Health Organization Copyright (c) World Health Organization 2015; 2015. 
3. Tatsilong HO, Noubiap JJ, Nansseu JR, Aminde LN, Bigna JJ, Ndze VN, et al. Hepatitis B infection awareness, vaccine perceptions and uptake, and serological profile of a group of health care workers in Yaounde Cameroon. BMC Public Health. 2016;15:706.

4. Shiferaw $Y$, Abebe T, Mihret A. Hepatitis B virus infection among medical aste handlers in Addis Ababa Ethiopia. BMC Res Notes. 2011:4:479.

5. Ogoina D, Pondei K, Adetunji B, Chima G, Isichei C, Gidado S. Prevalence of hepatitis B vaccination among health care workers in Nigeria in 2011-12. Int J Occup Environ Med. 2014;5(1):51-6.

6. Levanchy D. Hepatitis B virus epidemiology, disease burden, treatment, and current and emerging prevention and control measures. J Viral Hepat. 2004 Mar;11(2):97-107.

7. WHO. Weekly epidemiological record; 2009. p. 405-20. URI: https://www who.int/wer/2009/wer8440/en/

8. WHO. Key facts, Hepatitis B Virus. 2016. URI: https://www.who.int/topics/ hepatitis/factsheets/en/

9. WHO. Global Health Sector Strategy on Vial Hepatitis 2016-2021. 2016. UR: https:/apps.who.int/iris/bitstream/handle/10665/246177/WHO-HIV-2016.06eng.pdf;jsessionid=6E9DCC77B833E68E1148F506FCBB4A51? sequence $=1$

10. Topuridze M, Butsashvili M, Kamkamidze G, Kajaia M, Morse D, McNutt LA. Barriers to hepatitis B vaccine coverage among healthcare workers in the republic of Georgia: an international perspective. Infect Control Hosp Epidemiol. 2010;31(2):158-64.

11. Pellissier G, Yazdanpanah Y, Adehossi E, Tosini W, Madougou B, Ibrahima K, et al. Is universal HBV vaccination of healthcare workers a relevant strategy in developing endemic countries? The case of a university hospital in Niger. PLoS One. 2012;7(9):e44442.

12. Seid YK. Serological and Molecular Characterization of Hepatitis B, C and D Viruses Infections among Health Professionals in Ras Desta and Tikur Anbessa Hospitals, Addis Ababa, Ethiopia. In: A thesis submitted to Addis Ababa University digital library, Addis Ababa, Ethiopia; 2005. Unpublished.

13. Abeje $G$, Azage M. Hepatitis B vaccine knowledge and vaccination status among health care workers of Bahir Dar City Administration, Northwest Ethiopia: a cross sectional study. BMC Infect Dis. 2015;15:30.

14. Abebaw T, Aderaw Z, Gebremichael B. Hepatitis B virus vaccination status and associated factors among health care workers in Shashemene zonal town, Shashemene Ethiopia: a cross sectional study. BMC Res Notes. 2017; 10:260.

15. Bekele A, Tadesse A. Status of hepatitis B vaccination among surgeons practicing in Ethiopia: a cross sectional study. Ethiop Med J. 2014:52(3):107-12.

16. Ayalew MB, Horssa BA, Getachew N, Amare S, Getnet A. Knowledge and attitude of health care professionals regarding hepatitis $B$ virus infection and its vaccination, University of Gondar Hospital, Ethiopia. Hepatic Med Evidence Res. 2016;8:135-42.

17. Malewezi B, Omer SB, Mwagomba B, Araru T. Protecting health workers from nosocomial hepatitis $B$ infections: a review of strategies and challenges for implementation of hepatitis B vaccination among health workers in sub-Saharan Africa. J Epidemiol Glob Health. 2016;6(4):229-41.

18. Molla S, Munshea A, Nibret E. Sero-prevalence of hepatitis B surface antigen and anti HCV antibody and its associated risk factors among pregnant women attending maternity ward of Felege Hiwot referral hospital, Northwest Ethiopia: a cross-sectional study. Virol J. 2015;12:204.

19. Schillie S, Murphy TV, Sawyer M, Ly K, Hughes E, Jiles R, et al. CDC guidance for evaluating health-care personnel for hepatitis $B$ virus protection and for administering post-exposure management. MMWR Recomm Rep. 2013; 62(Rr-10):1-19.

20. Feleke BE. Low coverage of hepatitis $B$ vaccine and determinants among health professionals working in Amhara regional Sstate hospitals Ethiopia. J Public Health Afr. 2016;7:553.

21. Harapan H, Anwar S, Bustamam A, Radiansyah A, Angraini P, Fasli R, et al. WTP for a dengue vaccine and its associated determinants in Indonesia: a community-based, cross-sectional survey in Aceh. Acta Trop. 2017;166:249-56

22. Slunge D. The WTP for Vaccination against Tick-Borne Encephalitis and Implications for Public Health Policy: Evidence from Sweden. PLOS ONE. 2015;10(12): e0143875. https://doi.org/10.1371/journal.pone.0143875.

23. Hou Z, Jie C, Yue D, Fang H, Meng Q, Zhang Y. Determinants of willingness to pay for self-paid vaccines in China. Vaccine. 2014;32(35):4471-7.

24. Worasathit R, Wattana W, Okanurak K, Songthap A, Dhitavat J, Pitisuttithum $P$. Health education and factors influencing acceptance of and WTP for influenza vaccination among older adults. BMC Geriatr. 2015;15:136.
25. Harapan H, Mudatsir M, Yufika A, Nawawi Y, Wahyuniati N, Anwar S, et al. Community acceptance and willingness-to-pay for a hypothetical Zika vaccine: a cross-sectional study in Indonesia. Vaccine. 2019;37:1398-406.

26. Rajamoorthy Y, Radam A, Taib NM, Rahim KA, Munusamy S. Abram Luther Wagner AL., et al. willingness to pay for hepatitis B vaccination in Selangor, Malaysia: a cross-sectional household survey. PLoS One. 2015;14:4.

27. The Health System of Ethiopia. http://www.aho.afro.who.int/profiles_ information/index.php/Ethiopia:Service_delivery_-_The_Health_System accessed on July 22, 2019.

28. WHO. Combating Hepatitis B and C to Reach Elimination by 2030. 2016 URl: https://www.afro.who.int/sites/default/files/2017-06/WHO_HIV_2016.04_ eng.pdf

29. Nasir K., Khan KA., Kadri WM., et al. Hepatitis B vaccination among health care workers and students of Allama lqbal medical college, Lahore, Pakistan, 1998. URI: https://pdfs.semanticscholar.org/3a8d/3d2e64d2f6eb9551fe35d5 96423ed4cca728.pdf

30. Yogambigai R. Determinants of willingness to pay for hepatitis B vaccination in Malaysia Pertanika. J Soc Sci \& Hum. 2017;25(2):635-46.

31. Tarekegn AA, Mengistu MY, Mirach TH. Health professionals' willingness to pay and associated factors for cervical cancer screening program at College of Medicine and Health Sciences, University of Gondar, Northwest Ethiopia. PLoS One. 2015:14:4

32. Sardar A, Yaseen MR, Abbas A, Waqas M, Gill BA. Willingness to pay for vaccination against hepatitis $b$ and its determinants: the case study of an industrial district of Pakistan. Epidemiology Biostatistics and Public Health 2018:15(4):e12954-6. https://doi.org/10.2427/12954

33. Kumlachew A, Alemayehu W, Shimels H, Ayalew A. Association between socioeconomic status and willingness to pay for medical care among government school teachers in Addis Ababa. Sci J Public Health. 2015;3: 677-85.

34. Azimatun AN, Saperi S, Syed AM. Factors influencing willingness to pay for health care. BioMed Central Public Health. 2012;12:A37.

35. Javan N, Zahra K, Ahmad F, Mohammad K. Identification determinant factors on willingness to pay for health services in Iran. Heal Econ Rev. 2017;7:40.

\section{Publisher's Note}

Springer Nature remains neutral with regard to jurisdictional claims in published maps and institutional affiliations.

Ready to submit your research? Choose BMC and benefit from:

- fast, convenient online submission

- thorough peer review by experienced researchers in your field

- rapid publication on acceptance

- support for research data, including large and complex data types

- gold Open Access which fosters wider collaboration and increased citations

- maximum visibility for your research: over $100 \mathrm{M}$ website views per year

At $\mathrm{BMC}$, research is always in progress.

Learn more biomedcentral.com/submissions 